\title{
Editorial
}

\section{Environmental class actions; marine alien invasive species; urban biodiversity; domestic waste management; and housing rights in the face of typhoons}

\section{APJEL IN THE ASIA-PACIFIC REGION}

This first issue of APJEL in the 2021 volume features articles on environmental issues relevant to particular Asia states, and to the Asia-Pacific region generally. The five articles in this issue follow the eight in 2020 and 13 in the 2019 volume, which concerned environmental law developments in Australia, Bangladesh, China, Indonesia, the Maldives, Malaysia, New Zealand, Papua New Guinea, Singapore, the South China Sea region and Thailand.

It is clear that there is growing scholarly interest in environmental law and policy in the Asian-Pacific region. Our 2018 volume included articles on Australia, China, Fiji, India, Indonesia, Japan, Solomon Islands and Thailand. Before that, our 2017 volume included articles on aspects of environmental law in Australia, China, India, Japan and South Korea.

The range of subject matters covered is broad. Subjects examined in just the last two years include biodiversity protection in forests in Indonesia; biopiracy in Southeast Asia; carbon emission trading in China; compensation for soil pollution in China; corruption and forestry in Papua New Guinea; environmental conservation in the Maldives; genetically modified organisms in New Zealand; the grant of legal rights to rivers in Bangladesh; green banking in Bangladesh and China; logging in Australia; marine spatial planning in Bangladesh; noise pollution underwater; protection of birdlife migrating between Australia and China; public interest litigation in China; understanding and employing Islamic law to help protect environments in Indonesia, Malaysia and Singapore; and many more.

Our firm collective belief is that APJEL is making a valuable and continuing contribution toward advanced scholarship in the region; and that there is growing interest in publishing in this region.

We welcome both submissions of general environmental relevance and submissions on specific, focused issues, as long as both are of relevance to Asian-Pacific scholarship. APJEL's goal remains to publish analytical research on a broad range of environmental law issues across the Asia Pacific. The articles we seek to publish will always demonstrate high quality scholarship through both broad considerations of globally relevant issues and fine analyses of specific developments in environmental law in specific jurisdictions.

\section{DELAYS AND CHANGED PLANS IN 2021}

APJEL continues to publish rigorous scholarship in environmental law in the Asia-Pacific region and the five articles in this first issue of the 2021 volume will, we believe, make a valuable contribution toward such research and enhanced understanding. 


\subsection{The best laid plans}

Heading toward 2021 we had planned to have a research focus on the Convention on Wetlands ${ }^{1}$ and the 50th 'birthday' of what has been described as 'the only global treaty to focus on a single ecosystem'. ${ }^{2}$ We had planned also a research focus on the Convention on Biological Diversity, $1992^{3}$ (the 'CBD') and its Strategic Plan 2011-2020 ${ }^{4}$ with five strategic goals and 20 targets (known as the Aichi Biodiversity Targets) which it was hoped would be achieved by $2020 .^{5}$

These plans have had to be temporarily delayed in the context of the global COVID-19 pandemic which disrupted many international events in 2020 and 2021. The 15th Meeting of the Conference of Parties to the CBD was to have met in 2020 , but this has been postponed several times - the Meeting is now due to take place in October $2021 .^{6}$

We will return to these themes soon and we invite scholars working on these issues to contact us.

\subsection{Delay}

For many reasons, APJEL was affected in late 2020 and early 2021 by the new reality of COVID-19 - and our team of volunteer editors has struggled both with our own workloads and with the commissioning, editing, reviewing and rewriting of submitted articles. This has necessitated a delay and this first issue of 2021 is appearing some four months later than usual. To our contributors and our readers we offer our apologies.

\section{THE ARTICLES IN THIS ISSUE}

\subsection{Environmental class actions in Australia}

While most environmental activists, campaigners and lawyers undoubtedly prefer to avoid litigation, there will probably always be occasions when it is one or the most appropriate driver for necessary reform. Litigation is, of course, both risky and costly. Class actions provide a means to spread costs and risks; and, perhaps more importantly, to broaden participation.

The first article ${ }^{7}$ in APJEL's 24th volume is by Brooke Dellavedova, who explains that class actions enhance access to justice and the integrity of democratic processes

1. Originally adopted as the Convention on Wetlands of International Importance especially as Waterfowl Habitat. Ramsar (Iran), 2 February 1971, UNTS 14583 (entered into force 21 December 1975).

2. Ramsar.org, 'The Ramsar Convention: What's it all about?' The Ramsar Convention Secretariat (2015) available at <www.ramsar.org/sites/default/files/fs_6_ramsar_convention. pdf $>$ accessed 27 September 2020.

3. Convention on Biological Diversity, 5 June 1992, 1760 UNTS 142 (entered into force 29 December 1993).

4. CBD, 'Strategic Plan for Biodiversity 2011-2020, including Aichi Biodiversity Targets' (2010) available at $<$ www.cbd.int/sp/>.

5. CBD, 'Aichi Biodiversity Targets' (2010) available at <www.cbd.int/sp/targets/>.

6. CBD, <www.cbd.int/article/new-dates-cop15-october-2021> accessed 1 July 2021.

7. 'The role and impact of environmental class actions in Australia'. 
by providing a mechanism for grouping together 'like' claims. Environmental class actions, the author argues, have an important role to play in environmental governance including by providing compensation and remediation, shaping norms of conduct and promoting accountability. However, it must be admitted that there are various limitations on the usefulness of class actions in achieving environmental objectives. In particular, the regime governing class actions is procedural rather than substantive (not overcoming limitations on the availability or utility of causes of action for addressing environmental harm); it means that additional rules and jurisprudence are necessary, which may make some actions more difficult or inappropriate; and class actions may be both expensive and risky. Accordingly, the author suggests that we are unlikely to see 'the opening of the dreaded floodgates'; and that, instead, environmental governance is likely to continue to be supported by the appropriate and considered commencement and conduct of meritorious actions.

\subsection{Marine invasive alien species in Australia}

As our world becomes more interconnected, it is increasingly the case that local biodiversity is affected by the arrival of new species. The impacts of such arrivals are better understood in terrestrial, rather than marine, environments - and we urgently need to understand more about marine environments.

The second article ${ }^{8}$ in the present issue is by Kenny $\mathrm{Ng}$. In an increasingly globalized world, the threats posed by marine invasive alien species (sea-based organisms that are non-native to a marine ecosystem, and which can or have spread to a degree that has an adverse impact on biodiversity and human livelihoods) are ones that we have to adapt to. In Australia, threats from such species are exacerbated by the country's unique characteristics such as its sheer size, as well as its geographical and historical isolation from the rest of the world. Further, Australia's unique constitutional framework that entrenches its national system of federalism has led to complex power-sharing arrangements between the Commonwealth and the State and Territory governments. These arrangements complicate the effective management of invasive alien species. The article considers how marine invasive alien species are managed within the Australian legal framework, and what might be done to improve the status quo. The optimistic argument is made that marine invasive alien species can be effectively managed under a strong legal framework (based on sound domestic laws and institutions, and enhanced by greater international cooperation) which prevents as far as possible the occurrence of such species; and which minimizes their negative impacts.

\subsection{Urban biodiversity in Australia}

While we have a great deal of understanding of the damage that urbanization has done, and is doing, to biodiversity, there has been comparatively little research into the extent to which biodiversity may be maintained - and might in some circumstances even flourish - in urban environments.

The third article 9 in this issue is by Lachlan Penninkilampi, who argues that urbanization may be the most severe and irreversible driver of environmental change,

8. 'Combating marine invasive alien species effectively in Australia'.

9. 'Law reform for life: how to unleash the guiding principles of ecologically sustainable development to improve human relationships with (the rest of) urban biodiversity'. 
particularly with respect to biodiversity; but that, paradoxically, biodiversity can flourish in urban environments, and law and policy may be employed to enhance this flourishing. The article begins by outlining current approaches to urban biodiversity; then analyses the current state of biodiversity governance in Australia, focusing particularly on the laws and policies of the Commonwealth, New South Wales and local governments in Greater Sydney. Finally, the article details a program of reform which revisits the original guiding principles of ecologically sustainable development, considering how these principles might be used to foster better governance of urban biodiversity with respect to decision-making, the administration of law, issues at scale, the economy, valuation techniques and community participation. The proposed reform program includes not only systemic and multi-scalar reforms, but also locallevel reforms which have significant yet often overlooked potential to encourage everyday behaviour that is protective of biodiversity. The ultimate aim of the article, according to the author, is to explain some ways in which a more biodiverse urban future can be imagined, recognized, understood, valued, protected and enhanced as Australia develops in the twenty-first century.

\subsection{Domestic waste management in Singapore}

Environments worldwide are affected negatively by urbanization and its concomitant generation of waste - both industrial and domestic.

The fourth article ${ }^{10}$ is by Rosie Syme, who explains that effective waste management systems are essential infrastructure; and that in recent decades there has been growing awareness of the scale, breadth and immediacy of adverse impacts on environments of the enormous (and increasing) amounts of waste generated by people in urban environments. Singapore is the author's case study; and she explains that Singapore has committed to a 'zero waste' future despite having a traditionally high waste output and a waste management system dependent on waste incineration as the primary means of disposal. In the article a review of domestic waste management policy and law in Singapore is presented; and gaps in the legal framework are identified and considered. The conclusion is reached that there is a material environmental vulnerability in the legal framework that should be redressed in order to entrench environmental protections and to align the law with Singapore's policy ambitions. However, the article ends on an optimistic note for the future of domestic waste management in Singapore, especially because the government has made an ambitious policy commitment and appears to be in earnest about achieving it.

\subsection{Typhoons and housing in the Philippines}

One of the biggest challenges faced by states, especially in the developing world, confronting the challenges of a world in which climates are rapidly changing, is the sudden and massive natural disaster that displaces many thousands of people.

The fifth and final article ${ }^{11}$ in this issue is by Amiel Ian Valdez, who notes that, due to anthropogenic climate change, an era of 'super typhoons' has arrived. Drawing on the Philippine experience of such typhoons, which experience has included losses

10. 'A review of domestic waste management policy and law in Singapore'.

11. 'A continuing mandamus to enforce rights to adequate housing in the Philippines in the era of super typhoons'. 
of lives, displacements of people and damage to houses, properties and livelihoods, the article considers the legal standard of the right to adequate housing under both international human rights law and international climate change law, and the Philippines' commitments to these regimes. It is argued that post-typhoon responses by the Philippine government have been fragmented, reactive and ephemeral, and that the current housing laws contain significant gaps. It is then argued that these issues are incongruent with minimum required standards for adequate housing; and that domestic courts may play an important role in enforcing the government's adaptation commitments under the Paris Agreement, especially if using the writ of continuing mandamus.

\section{COMMENT}

We believe that every article we publish represents an under-appreciated collaborative relationship between authors, anonymous reviewers, editors and publishers. As always, the editorial team would like to note that while we cannot thank in print the anonymous reviewers upon whose expertise we rely in the review process, we acknowledge that their input strengthens considerably the scholarship contained in the articles that we publish - we are very grateful to them!

Ed Couzens and Tim Stephens

Editors

Assisted by

Cameron Holley

Faculty of Law, University of New South Wales

Saiful Karim

Faculty of Law, Queensland University of Technology

Kate Owens

The University of Sydney Law School

Manuel Solis

Manila Observatory

Katie Woolaston

Faculty of Law, Queensland University of Technology 